\title{
Correlation of anthropometric parameters on blood pressure in normotensive males.
}

\author{
Sunitha $\mathrm{P}^{\mathrm{a}}$, Satyanarayana $\mathrm{N}^{\mathrm{b}}$ \\ ${ }^{a}$ Lecturer, Department of physiology, AIMST University, Semeling, 08100 Bedong ,Kedah Darul Aman,Malaysia. \\ ${ }^{b}$ Lecturer, Department of Anatomy, AIMST University, Semeling, 08100 Bedong ,Kedah Darul Aman,Malaysia. \\ A. Dr. P. Sunitha. Lecturer (Faculty of medicine), Department of Physiology, AIMST University, Semeling, 08100 \\ Bedong, Kedah Darul Aman, Malaysia. \\ B. Dr Namani Satyanarayana. (Faculty of medicine), Department of Anatomy, AIMST University, Semeling, 08100 \\ Bedong, Kedah Darul Aman, Malaysia.
}

\begin{abstract}
Hypertension is most common disorder worldwide. The prevalence of hypertension is increasing. In the present study an attempt has been made to examine the effect of anthropometric parameters on blood pressure in normotensive males. The present study was carried out in physiology department, Prathima Medical College, Karimnagar, (A.P.), India. Subjects were mainly staff of Prathima Medical College and old age home, Karimnagar. Included male subjects who had no significant aliments. This was done in accordance with joint national committee report guidelines. According to the study, it can concluded that BMI,WHR, showed a statistically significant positive correlation with diastolic blood pressure. But age did not show the expected impact on either systolic or diastolic blood pressure.
\end{abstract}

Keywords: hypertension, BMI, WHR.

\section{INTERDUCTION}

The prevalence of Hypertension is increasing throughout the world. Many of the previous landmark intervention trials have focused on the reduction in the risk factor such as Hypertension and its effect on cardiovascular, cerebrovascular and microvascular events as primary out come.

Cardiovascular disease (CVD) is established as the main cause of death in virtually all industrialized countries of the world. The epidemiology of CVD is rapidly changing in developing countries. It appears from secular trends that CVD comprising of coronary artery disease (CAD) and stroke are becoming more common in developing countries. Hypertension is an important risk factor for both CAD and stroke.

Hypertension is not only one of the major risk factors of CVD but it is a condition with its own risk factors. A WHO scientific group has recently reviewed the risk factors for essential hypertension ${ }^{1}$. They may be classified as: Non-modifiable risk factors: Age, Genetic factors and Modifiable risk factors: Obesity/truncal obesity, Salt intake, Saturated fat, Alcohol, Physical activity, Environmental stress. Increasing prevalence of hypertension may be a manifestation of urbanization of westernization of traditional societies. Similarly less is known about how the anthropometric parameters affect the normal blood pressure. Hence through this cross sectional study an attempt is made to understand the influence of Age, Body Mass Index (BMI), Waist Hip Ratio (WHR), on blood pressure among adult men below and above the age of 60 years.

\section{MATERIALS AND METHODS \\ Selection of subjects}

This study was done in the Physiology department of Prathima Institute of Medical Sciences, Karimanagar(A.P.), India and included subjects based on the following criteria:A total of 40 males were included in the study and divided in to two groups. One of the groups included younger males with the age between 18 to 59 years while other group included older males 60 years of age.This was done in accordance with the Joint National Committee report VI guidelines ${ }^{2}$. Twenty healthy males were included in each of the two groups. Subjects were mainly staff of Prathima Medical College. The elderly subjects were chosen mainly from old as Home in Karimnager, who had no significant ailments. Care was taken to choose subjects who were not suffering from any major illness at present or in the recent past. Normal Blood Pressure was defined as systolic Blood pressure less than $140 \mathrm{mmHg}$ and diastolic blood pressure less than $90 \mathrm{mmHg} .^{2}$ A prior informed consent was obtained from each subject for participation in the study and was briefed about the procedure to achieve full cooperation. The following physical characteristics were measured: Height, Weight, Body Mass Index, Waist Hip Ratio, Blood Pressure. 


\section{Anthropometric Variables}

a) Body Weight: This was measured in the erect position without footwear with the subject lightly clothed. Measurements were taken with the same instrument and were done in kilograms which were rounded off to the nearest half a kilogram.

b) Height: After removing the shoes subject was asked to stand upright on the flat floor keeping the feet parallel to heels, buttocks, and shoulder and back of the head touching a hard surface. The head was held comfortably erect with the lower border of the orbit in the same horizontal plane as the external auditory meatus. The arms were positioned by the side of the body. Measurements were taken to an accuracy of half a centimeter.

c) Body mass index (BMI): This was calculated as weight (in kilograms) divided by (height in meters)

d) Waist to Hip Ratio(WHR): Waist circumference was measured at the navel while person was breathing quietly and hip circumference was measured at the intertrochanteric line using a steel tape as per previously recommended methodology $y^{3}$. The ratio of the above two physical parameters was calculated and was rounded of to the nearest two decimal.

\section{Recording of Blood Pressure:}

Blood pressure measurements were done in the morning hours between 8.00 and $10.00 \mathrm{a}$.m. The same mercury sphygmomanometer was used for all subjects and BP was measured using the auscultatory method. The equipment was checked and calibrated for its accuracy as per the recommendations by British Hypertension Society ${ }^{4}$.Measurements were taken in the sitting position. Tight fitting clothing was removed. The cuff was applied firmly on the left arm, which was supported at the level of the heart. Care was taken to give five minutes rest to the subject prior to first measurement. The second measurement was taken 30 minutes later. The subject was kept free from smoking and caffeine during this interval. The third reading was taken on the fifth day. The average of the three readings was taken as the blood pressure of the individual. Both SBP and DBP were measured.

\section{STATISTICAL ANALYSIS:}

Data thus obtained was analyzed. The values were considered statistically significant $(\mathrm{p}<0.05)$ when the $\mathrm{P}<0.05$. The results obtained were confirmed using multiple regression analysis. Correlation coefficients (r) were calculated using Pearson correlation.

\section{RESULTS}

A total of 40 subjects were included in the study. All subjects were normotensive males.

Table-1

\begin{tabular}{|c|c|c|c|c|c|c|c|c|c|c|}
\hline a) & \multicolumn{4}{|c|}{$\begin{array}{l}\text { Values of parameters recorded in the } \\
\text { ge group < } 60 \text { years }\end{array}$} & \multicolumn{6}{|c|}{$\begin{array}{l}\text { b) Values of parameters recorded in the age group } \geq 60 \\
\text { years }\end{array}$} \\
\hline S.N. & AGE & SBP & DBP & BMI & WHR & AGE & SBP & DBP & BMI & WHR \\
\hline 1 & 20 & 124.66 & 71.33 & 24.80 & 0.87 & 60 & 139.33 & 79.33 & 21.5 & 0.89 \\
\hline 2 & 21 & 111.33 & 74.66 & 20.81 & 0.88 & 61 & 90.66 & 60.66 & 14.98 & 1.00 \\
\hline 3 & 22 & 133.33 & 80.66 & 24.74 & 0.92 & 65 & 129.33 & 76.66 & 17.85 & 0.90 \\
\hline 4 & 24 & 138.66 & 88.66 & 27.41 & 0.95 & 66 & 100.66 & 69.33 & 19.92 & 0.88 \\
\hline 5 & 29 & 127.33 & 82.66 & 25.00 & 0.94 & 66 & 120.66 & 79.33 & 19.14 & 0.91 \\
\hline 6 & 30 & 110.00 & 81.33 & 26.90 & 0.94 & 66 & 139.33 & 79.33 & 25.4 & 1.00 \\
\hline 7 & 30 & 132.66 & 82.00 & 27.47 & 0.97 & 66 & 110.66 & 88.66 & 26.89 & 0.79 \\
\hline 8 & 32 & 120.66 & 82.66 & 27.76 & 0.95 & 69 & 130.00 & 88.66 & 20.08 & 0.92 \\
\hline 9 & 38 & 130.00 & 80.66 & 24.40 & 0.96 & 70 & 101.33 & 60.66 & 19.84 & 0.97 \\
\hline 10 & 39 & 134.00 & 81.33 & 25.18 & 0.94 & 71 & 130.66 & 80.00 & 26.89 & 1.00 \\
\hline 11 & 41 & 118.00 & 88.66 & 24.24 & 0.94 & 71 & 110.66 & 66.66 & 24.45 & 0.97 \\
\hline 12 & 41 & 134.00 & 80.66 & 25.90 & 0.92 & 72 & 108.66 & 66.66 & 19.93 & 0.92 \\
\hline 13 & 42 & 122.00 & 82.66 & 27.26 & 0.97 & 74 & 129.33 & 88.66 & 25.53 & 1.00 \\
\hline 14 & 42 & 120.66 & 80.00 & 25.91 & 0.88 & 74 & 113.33 & 80.00 & 20.01 & 0.94 \\
\hline 15 & 47 & 110.33 & 83.33 & 24.22 & 0.91 & 76 & 139.33 & 80.66 & 22.32 & 1.00 \\
\hline 16 & 48 & 110.66 & 79.33 & 25.34 & 0.92 & 81 & 110.66 & 70.00 & 24.8 & 0.90 \\
\hline
\end{tabular}




\begin{tabular}{|l|l|l|l|l|l|l|l|l|l|l|}
\hline 17 & 49 & 120.00 & 80.00 & 22.65 & 0.94 & 82 & 109.33 & 80.66 & 23.03 & 0.92 \\
\hline 18 & 49 & 122.00 & 82.66 & 27.24 & 0.97 & 82 & 139.33 & 88.66 & 16.13 & 0.89 \\
\hline 19 & 59 & 130.00 & 88.66 & 25.14 & 1.00 & 83 & 138.66 & 60.00 & 20.07 & 0.92 \\
\hline 20 & 57 & 136.66 & 81.33 & 24.74 & 0.93 & 83 & 139.33 & 80.00 & 18.02 & 0.94 \\
\hline $\begin{array}{l}\text { Age } \\
\text { Range }\end{array}$ & $20-59$ & $\begin{array}{l}110.00 \\
\text { to } \\
138.66\end{array}$ & $\begin{array}{l}71.33 \\
\text { to } \\
88.66\end{array}$ & $\begin{array}{l}20.81 \\
\text { to } \\
27.76\end{array}$ & $\begin{array}{l}0.87 \\
\text { to } 1\end{array}$ & $\begin{array}{l}60 \\
83\end{array}$ & $\begin{array}{l}90.66 \text { to } \\
139.33\end{array}$ & $\begin{array}{l}60 \text { to } \\
88.66\end{array}$ & $\begin{array}{l}14.98 \text { to } \\
26.89\end{array}$ & $\begin{array}{l}0.79 \\
\text { to } 1 \\
\text { Average }\end{array}$ \\
\hline SD & 124 & 124.35 & 81.66 & 25.36 & 0.94 & 71.9 & 121.562 & 76.229 & 21.339 & 0.93 \\
\hline
\end{tabular}

Table 1 (a) lists the values for all the parameters recorded for each of the twenty males below the age of 60 years. In this group of Individuals age ranged from 20-59 years. SBP ranged from 110 to $138.66 \mathrm{~mm}$ of $\mathrm{Hg}$ while DBP ranged between 71.33 and $88.66 \mathrm{~mm}$ of $\mathrm{Hg}$. BMI was in the range of 21.81 to $27.76 \mathrm{Kg} / \mathrm{m}^{2}$. WHR was between 0.87 and 1.

Table 1(b) reflects the values for men 60 years of age and above. SBP was in the range of 90.66 to $139.33 \mathrm{~mm}$ of $\mathrm{Hg}$ and DBP was from 60 to $88.66 \mathrm{~mm}$ of $\mathrm{Hg}$. BMI ranged between 14.98 and $26.89 \mathrm{~kg} / \mathrm{m}^{2}$ and WHR ranged from 0.79 to 1.00 .

Table-2

\begin{tabular}{|c|c|c|c|c|}
\hline \multicolumn{5}{|c|}{$\begin{array}{l}\text { Analysis of means of the parameters in both the age } \\
\text { groups }\end{array}$} \\
\hline \multirow[t]{2}{*}{ VARIABLE } & $\begin{array}{l}<\quad 60 \\
\text { YEARS } \\
(n=20)\end{array}$ & $\begin{array}{l}\geq 60 \\
\text { YEARS } \\
(n=20)\end{array}$ & \multirow[t]{2}{*}{ VALUE } & \multirow[t]{2}{*}{$\begin{array}{l}\text { p- } \\
\text { VALUE }\end{array}$} \\
\hline & $\begin{array}{l}\text { MEAN } \pm \\
\text { SE }\end{array}$ & $\begin{array}{l}\text { MEAN } \pm \\
\text { SE }\end{array}$ & & \\
\hline SBP & $\begin{array}{l}124.35 \pm \\
2.07\end{array}$ & $\begin{array}{l}121.56 \pm \\
3.51\end{array}$ & 0.68 & $>0.10$ \\
\hline DBP & $\begin{array}{l}81.66 \pm \\
0.92\end{array}$ & $\begin{array}{l}76.23 \pm \\
2.14\end{array}$ & 2.33 & $>0.05$ \\
\hline BMI & $\begin{array}{l}25.36 \pm \\
0.39\end{array}$ & $\begin{array}{ll}21.34 \quad \pm \\
0.77\end{array}$ & 4.64 & $<0.001^{* *}$ \\
\hline WHR & $\begin{array}{l}0.94 \pm \\
0.01\end{array}$ & $\begin{array}{l}0.93 \pm \\
0.01\end{array}$ & 0.14 & $>0.10$ \\
\hline
\end{tabular}

Table 2 shows the mean values with the standard error of mean of blood pressure and all the other two parameters.

As seen from the table 2 the mean SBP in younger age group $124.35 \pm 2.07 \mathrm{~mm} \mathrm{Hg}$ that was higher than the mean value of $121.56 \pm 3.51$ of the older group and this was not found to be significant. The mean diastolic blood pressure was $81.66 \pm$ $0.92 \mathrm{mmHg}$ in the younger group was also higher than that of the older group $(76.23 \pm 2.14 \mathrm{mmHg})$ and this was not significant.

The younger age group showed a significantly higher $(\mathrm{p}<0.001)$ mean BMI of $25.36 \pm 0.39$ as compared to the 21.34 \pm 0.77 in the older adults males. Analysis of variance (ANOVA) was done to study the relationship of blood pressure with all the other parameters. The multiple linear regression analysis showed that BMI is significantly related ( $<<0.001)$ to the diastolic blood pressure. No other parameter showed any significant relationship to blood pressure. 
IOSR Journal of Pharmacy

Vol. 2, Issue 3, May-June, 2012, PP.593-598

\begin{tabular}{|c|c|c|c|c|}
\hline \multicolumn{5}{|c|}{$\begin{array}{l}\text { Pearson correlation between SBP, DBP and other parameters in both the age } \\
\text { groups }\end{array}$} \\
\hline \multirow[t]{2}{*}{ PARAMETER } & \multicolumn{2}{|c|}{ SYSTOLIC BLOOD PRESSURE } & \multicolumn{2}{|l|}{$\begin{array}{l}\text { DIASTOLIC } \\
\text { PRESSURE }\end{array}$} \\
\hline & $\begin{array}{l}<60 \text { YEARS } \\
\text { (r) }\end{array}$ & $\begin{array}{l}<60 \text { YEARS } \\
(\mathrm{r})\end{array}$ & $\begin{array}{l}\geq 60 \text { YEARS } \\
(\mathrm{r})\end{array}$ & $\begin{array}{l}\geq 60 \text { YEARS } \\
\text { (r) }\end{array}$ \\
\hline AGE & -0.014 & 0.359 & 0.064 & 0.270 \\
\hline BMI & 0.268 & 0.379 & 0.278 & 0.096 \\
\hline WHR & 0.319 & $0.708^{* * *}$ & -0.221 & 0.100 \\
\hline
\end{tabular}

Table-3: Systolic blood pressure ${ }^{*} \mathrm{p}<0.05$ - Significant, Diastolic blood pressure ${ }^{* *} \mathrm{p}<0.001$ - Highly Significant

Table 3 summarizes the results of this calculation and shows the correlation between SBP and other parameters in both age groups. There was a positive correlation between systolic blood pressure and BMI ( $r=0.268)$, WHR ( $\mathrm{r}=0.319)$, in the below 60 years age group although not significant.

In the elderly males systolic blood pressure showed a positive correlation with age $(r=0.270)$, BMI $(r=0.096)$, WHR $(r=0.1)$. Further in this group SBP was significantly correlated to DBP.

Correlation of diastolic blood pressure with other parameters was done similarly and has been depicted in table 5 . DBP was positively correlated to all the variables i.e. age $(r=0.359)$, BMI $(r=0.379)$, WHR $(r=0.708)$ in below 60 years age group. Among these, WHR $(r=0.708 \mathrm{p}<0.001)$ showed a strong statistically significant correlation with DBP in the younger group.

Table 3 also summarizes the results in the elderly males BMI $(r=0.270)$ were positively correlated to DBP while WHR ( $\mathrm{r}=$ -0.221 ), showed a negative correlation and these were not found to be statistically significant.

\begin{tabular}{|c|c|c|c|c|c|}
\hline \multirow[t]{2}{*}{ a) } & \multicolumn{2}{|c|}{$\begin{array}{l}\text { Pearson correlation between SBP and } \\
\text { DBP in both the age groups together }\end{array}$} & \multicolumn{3}{|c|}{$\begin{array}{l}\text { b) Effect of age on other parameters of } \\
\text { both age groups }\end{array}$} \\
\hline & SBP (r) & $\mathrm{DBP}(\mathrm{r})$ & PARAMETER & $\begin{array}{l}\text { AGE } \\
(\mathrm{r})\end{array}$ & P-VALUE \\
\hline AGE & -0.039 & -0.239 & SBP & -0.039 & $>0.10$ \\
\hline BMI & 0.173 & $0.433^{* *}$ & DBP & -0.239 & $>0.05$ \\
\hline WHR & 0.159 & -0.017 & BMI & $-0.522^{* *}$ & $<0.001$ \\
\hline & & & WHR & 0.073 & $>0.10$ \\
\hline
\end{tabular}

Table-4 ${ }^{* * *} \mathrm{p}<0.001$-Highly Significient

Table 4(a) represents the correlation of SBP and DBP in both age groups together with other variables. Both SBP and DBP showed a negative correlation with age. This was not statistically significant. As the BMI increased SBP and DBP also increased but this positive correlation was statistically significant for BMI vs. DBP $(r=0.433 \mathrm{p}<0.05)$. WHR showed a positive correlation with SBP.

Table 4(b) shows the effect of age on other variables across the age groups. it has been observed in our study that although SBP and DBP have a negative correlation with age, it is not significant. Body mass index significantly $(r=-0.522 \mathrm{p}<0.001)$ decreased as the age increased. 


\section{DISCUSSION}

This present study included the anthropometric indices (body mass index, waist to hip ratio) as the factors affecting blood pressure. Analysis of our results showed that the SBP and DBP in the younger age group was higher than that observed in the elderly.

While most studies in the past have suggested a gradual rise in BP with age this study has shown a gradual decline in blood pressure with age. Why this disparity? One most remember that this is not a longitudinal study. The individuals studied at different ages are not the same, as this is a cross-sectional study. And interestingly, it so happened that the BP of the younger age group was found to be higher than that of the elderly age group. So the apparent gradual fall in blood pressure with age can be attributed to the lower mean BP values in the older age group. It is most probably due to better lifestyle habits of the elderly age group, lesser exposure to high risk factors in the elderly age group. This was also the observation of Pan et $\mathrm{al}^{5}$ in which they highlighted the effect of lifestyle rather than age on blood pressure. This attributed to consumption of little salt, animal fat and maintaining good physical fitness. All these attributes were also seen in the elderly individuals in our study.

The mean BMI levels in younger age group were significantly higher showing that the higher levels of BP might be due to higher BMI in this group. This was in accordance with the findings of Beall ${ }^{6}$ et al , Masaki ${ }^{7}$ et al, Bravoluna ${ }^{8}$ et al and Stamler ${ }^{9}$ et al, Babu ${ }^{10}$, Doll ${ }^{11}$ et al . All these studies have shown a positive relationship of BMI with blood pressure. In our study this was confirmed by multiple linear regression analysis.

In this study WHR was higher in the younger age group and was significantly correlated with DBP. This was also the finding of Gupta et $\mathrm{al}^{12}$ and Folsom et al. ${ }^{13}$

Thus in this study BMI which is a measure of body habitus and WHR, a marker of truncal obesity have been associated with a blood pressures within the normal range. Our study has shown that the Body Mass Index and Waist hip ratio in the normal ranges affect blood pressure. So these parameters might be considered as the factors, which can be included under the primary prevention of hypertension at an early stage.

\section{CONCLUSION}

The effect of age on blood pressure was the objective of this present study. The effect of some significant anthropometric parameters was studied, analyzed and interpreted with reference to various similar Indian and Western studies.

The following conclusions were drawn from the present study.(1) The body mass index was found to be the most statistically significant parameter that affects the diastolic blood pressure irrespective of the age.(2) Age per se did not show the expected impact on either systolic or diastolic blood pressure. This was probably due to the cross sectional nature of the study.(3) As far as the diastolic blood pressure in the lower age group was concerned the waist hip ratio showed a statistically significant positive correlation. 


\section{REFERENCES}

[1]. Techn. Rep. Ser.WHO 1983; 686.

[2]. The sixth report of Joint National Committee on prevention detection evaluation and treatment of high blood pressure, Arch intern Med. 1997; 157:2413-2446

[3]. R Gupta and S. mehrishi, waist hip ratio and blood pressure correlation in an urban indian population, J. Indian med Assoc 1997; 95; 412-415.

[4]. JC.Petvie, ET. O'brian, WA.Littler, M.Deswiet. Recommendations on blood pressure measurement. B. Med J. 1986 Sept; 293:611-615.

[5]. W.Pan, S. Nanas, A. Dyer et al The role of weight in the positive association between age and blood pressure, Am J Epidemiol 1986;24:612-23.

[6]. CM.Beall, A. Gebremedhin ,GM. Brittenham et al, Blood pressure variation among Ethiopians on the Simian Plateau. Ann Hum Biol 1997; 24 (4): 333-342.

[7]. KH. Masaki , JD. Curb , D. Chiu et al.Association of BMI with blood pressure in elderly Japanese American men. The Honolulu heart program, Hypertension 1997;29(2): 673-7.

[8]. 8 M. Bravoluna , M. Orsstti, L. Poletto. The correlation of arterial with weight and body mass index, Gac Med Nex 1999; 135 (5): 463-70.

[9]. J. Stamber, AW. Caggiula , GA.Grandits. Relation of body mass and alcohol, nutrient, fibre, caffeine intakes to blood pressure in the special intervention and usual groups in the multiple risk factors intervention trial, Am J Clin Nutr. 1997; 65(1): Suppl S338-65.

[10]. RN. Chopra, GS. Chopra. A study of normal blood pressure in Indians, Indian Medical Gadzette 1947; 77:2122.

[11]. S. Doll, F.Paccaud, P. Bovet P et al. Body mass index, abdominal adiposity and blood pressure: consistency of their association across developing and developed countries, Int J Obes2002; 26: 48-57.

[12]. R.Gupta , S. Majumdar . Correlation of waist-hip ratio with coronary heart disease and risk factor prevalence in a rural male population, Indian Heart J 1994; 4:145-148.

[13]. AR. Folsom, GL.Burke, C. Ballew et al.Relation of body fatness and its distribution to cardivaskular risk factors $\mathrm{n}$ young Blacks and Whites, Am j Epidemiol 1989; 130:911-24. 